\title{
O CÓDIGO BEVILÁQUA COMO INSTRUMENTO DO PARADIGMA INDIVIDUALISTA
}

\section{THE BEVILÁQUA'S CODE AS AN INSTRUMENT IN FAVOR OF THE INDIVIDUALISTIC PARADIGM}

\section{Gustavo Henrichs Favero ${ }^{1}$}

Resumo: O presente ensaio visa proporcionar um panorama histórico-teórico acerca dos matizes filosóficos e metodológicos que inspiraram a elaboração do Código Civil de 1916, sua centralidade patrimonialista-individualista e como tal cosmovisão influenciou a edificação dos princípios contratuais então vigorantes.

Palavras-chave: Direito Civil. Liberalismo. Individualismo.
Abstract: The article has aimed to provide a historical and theoretical overview about the philosophical and methodological foundations that steeredthe authors of the 1916's Brazilian Civil Code, its property protection and individualistic centrality, and how this kind of worldview influenced the foundation of the contractual principles of that period.

Keywords: Civil Law. Liberalism. Individualism.

\section{INTRODUÇÃO}

Escreveu outrora o poeta Fernando Pessoa: "vivo sempre no presente; o futuro, não o conheço; o passado, já o não tenho". O passado é tudo o que não conseguimos ser. Por isso mesmo, qualquer estudo sério deve volver seus olhos à tradição pretérita-base estruturante do que se vive hodiernamente -.

Esta a razão do presente trabalho: retornar às origens do Código Civil de 1916 para (tentar) compreender o modelo atual. Não se trata de labuta pedante ou erudita, mas, de contribuição teórica honesta para o imprescindível entendimento do

1 Mestrando em Direito pela Universidade Federal de Santa Catarina (UFSC). Membro da Academia Brasileira de Direito Processual Civil. Professor convidado da Escola Superior da Advocacia de Santa Catarina (ESA/OABSC). Advogado. E-mail: ghfavero@gmail.com 
que se discute diuturnamente nos Tribunais pátrios, principalmente ao que tange o tema "contratos".

O método empregado para a elaboração do texto foi o dedutivo, por meio de pesquisa bibliográfica vocacionadas às fontes primárias e secundárias.

\section{A DOGMÁTICA JURÍDICA E A CONCEPÇÃO DE DIREITO NO ESTADO LIBERAL}

O Estado Liberal de Direito, face à imperiosa necessidade de solapar, ou ao menos, mitigar os incites e desmandos d'um regime que lhe antecedera, erigiu como vetor fundamente o princípio da legalidade como sua gênese (ACKERMAN, 1991, p. 34). Tal instrumentalização teórica elevou a lei a um ato supremo, com fulcro de se extirpar as tradições jurídicas do absolutismo e do ancien regime (ROIG, 2003, p. 55).

Todavia, o primado da legalidade constituir tão somente efêmera fórmula encontrada pela burguesia para substituição do regime de outrora (BAYNES, 2000, p. 77). Mister não esquecer que a ideia precípua do postulado da legalidade é de que uma qualidade essencial de toda a lei é adstringir e limitar a liberdade individual (BICKEL, 1986, p.101). Paradoxalmente, para haver intromissão na liberdade individual, a lei deveria ser aprovada com a chancela popular, inobstante a ordenação do Rei. De tal modo a lei passou a ser, ontologicamente, o ato produzido mediante cooperação da representação popular. Ato contínuo, o império da lei se transmudou em império da representação popular (SCHMITT, 1982, p. 157).

Diante disso, e, grosso modo, na tradição anglo-saxônica a legislação pôde ser conjurada com demais valores, exsurgindo um sistema jurídico complexo (common Law), enquanto que nos países de tradição romano-germânica, o direito foi amesquinhado à tão somente a lei (ZAGREBELSKY, 2003, p. 25).

Vislumbra-se que na idealização monolítica de um Estado 
de Direito Liberal, a burguesia adotou uma asserção de lei que repousa em uma secular tradição européia (CANARIS, 2003, p. 243) - herança da filosofia grega, que passou à Idade Média através da escolástica (NEDEL, 2006, p. 109) - conforme se dessume que a lei não é a vontade de um ou de uma turba de homens, mas algo geral-racional (OLIVEIRA, 1985, p. 93) que em seu processo de afirmação vale precisamente por ser ordem, não havendo o porquê se imiscuir em seus caracteres morais ou lógicos (NORR, 2004, p. 141).

A dogmática jurídica e toda a concepção de direito, portanto, fundamentada sob os auspícios do princípio da legalidade, acabou por se constituir em um critério de identificação do direito (FERRAJOLI, 2001, p. 52); o direito estaria na norma jurígena, cuja validação não pressuporia a interligação com um ideal de justiça, mas somente de ter sido produzida por autoridade dotada de competência legiferante (MELLO, 2004, p. 156). Nessa toada, Ferrajoli (2001, pg. 54), classifica-qualifica o princípio da legalidade como metanorma de reconhecimento das normas vigentes, acrescendo que, segundo tal primado, a norma jurídica existe e é válida em razão das formas de sua produção. Tal dimensão, destarte, afirma que a juridicidade da norma não dialoga com sua justiça intrínseca (LARENZ, 1997, p. 221), importando, como se asseverou supra, sua edição em conformidade com o procedimento vigente (FERRAJOLI, 2001, p. 53).

Antes do Estado legislativo, ou do advento do princípio da legalidade, o direito não decorria exclusivamente da lei, mas sim da jurisprudência e das teses doutorais. A fundação do Estado legislativo implicou em transformações das concepções até então reinantes de o que seria direito (GUASTINI, 1998, p. 97).

\section{BREVE ESCORSO HISTÓRICO ACERCA DO CÓDIGO CIVIL DE 1916 \\ O advento do Código Civil de 1916 culminou com a ab-}


rogação das Ordenações Filipinas então vigentes e vigorantes (COUTO E SILVA, 1987, p. 129). Justamente a procedência estatal portuguesa das ordenanças e a lacunosidade destas, fatores que ensejaram o "centralismo" e o "bartolismo", e conseguintemente, à pluralidade de influências teoréticas (PONTES DE MIRANDA, 1981, p. 102).

O senil "Código Beviláqua", tido por Pontes de Miranda (1981, p. 85), como o antepenúltimo código oitocentista-mui embora entrado em vigor em 1916 - por seu espírito individualista, liberal em matéria econômica, conservador ao extremo nas relações familiares, tornou-se referência meramente histórica com a votação do PL n. 635, de 1975, que se converteu no hodierno Código Civil.

Ao se aproximar o cinquentenário do antigo Código, a sociedade civil e jurídica bradava transformações. De um lado, os reclamos eram tributados a um movimento que tropegamente perambulava pelo continente europeu, a saber, o movimento da descodificação civil, sintetizando, décadas mais tarde, no paradigmático texto de Natalino Irti: L'età della decodificazione (1979). De mais a mais, não era compatível com o ethos do sistema brasileiro o individualismo então imperante e a incontestável avareza no trato de valores existenciais ligados à vida civil (REALE, 1987, p. 221). O monumento técnico do velho codex não se mostrava suficiente como justificação de sua permanência (FACHIN, 2003, p. 73).

A codificação civil liberal de antanho (Código Civil de 1916), de feição hialinamente individualista, detinha como valor indissociável à sua estrutura a realização da pessoa na e para sua propriedade (LORENZETTI, 1998, p. 253). Em torno da propriedade gravitavam as demais pretensões e garantias do indivíduo - máxime de interesses privados tuteláveis. O patrimonialismo, domínio inconteste sobre praticamente todos os bens, inclusive em face do arbítrio dos mandatários do poder 
político, realizava a pessoa humana (KELSEN, 1987, p. 183).

As relações civis eram eminentemente de cariz patrimonializante, bastando recordar que seus principais institutos eram a propriedade e o contrato (FACHIN, 2003, p. 118). Nesse norte, a prevalência exacerbada do patrimônio, como valor circundante a ser tutelado no Código, submergiu a pessoa humana (FACHIN, 2003, p. 119), que passou a figurar como polo de relação jurídica como sujeito abstraído de sua dimensão real (GADAMER, 2000, p. 334).

Presente então a supramencionada patrimonialização das relações civis, tornava-se incompatível qualquer valor emergente na dignidade da pessoa, adotada esta como baliza das constituições proclamadas no pós-guerra (LÔBO, 1986, p. 11).

O mais pessoal e emancipatório de toda ordem civil, o direito de família, era ele mesmo marcado pelo predomínio do conteúdo patrimonializante. No Código Civil de 1916, dos 290 (duzentos e noventa) artigos do Livro de Família, 151 (cento e cinquenta e um) são redigidos a salvaguardar interesses patrimoniais (FACHIN, 2003, p.81).

\section{AS SISTEMÁTICAS METODOLÓGICAS DO CÓDIGO OITOCENTISTA}

A autoproclamada "segunda sistemática" tem como pressuposto curial as teses racionais-cartesianas (CANARIS, 1989, p. 78), que, transportadas para as ciências jurídicas por Thomas Hobbes, ensejou uma sistematização fulcrada em sistema jurídico ao reverso do humanismo clássico (RODRIGUEZ, 1993, p. 203). Tal sistematização é central, isto é, uma concepção axiomática-dedutiva com o ideal de que todo sistema jurídico estaria assentado em poucos postulados, dos quais, entrementes o método lógico-dedutivo, os demais restariam obtidos - e, paralelamente, rejeitando os elementos histórico-culturais que se opunham ao cogito - (GARDIES, 1978, p. 128). 
Negando a natureza histórico-social-cultural da realidade fenomênica do jurígeno, importava, a sistemática jusnaturalista, que o Direito integrava as disciplinas que independiam das experiências factuais, sendo redutível ao método dedutivo lógico-matemático (mos geometricus), consoante escólio de Pontes de Miranda (1981, p. 93).

As codificações oitocentistas, como o Código Civil de 1916, estão assentadas em sistemáticas metodológicas "internas" e "fechadas" (CANARIS, 1989, p. 81), caracterizando-se pela unicidade das fontes legislativas, haja vista a Teoria Monista das Fontes do Direito então vigorante (PERLINGIERI, 1989, p. 8). Caracterizava-se, ademais, pela autorreferência absoluta e excludente de qualquer normatização não inserida no Código, em evidente vedação à heterointegração (PONTES DE MIRANDA, 1981, p. 109). Se isso não bastasse, também possuía como caractere primevo a edificação do plano jurídico sobre a mitológica autossuficiência, plenitude lógica e igualdade de todos ante à lei (CACHAPUZ, 1981, p. 33).

Desse modo, as codificações oitocentistas, verdadeiros monumentos culturais (AMARAL NETO, 1988, p. 34), são caracterizadas, no que tange à metodologia: por consubstanciarem sistemas fechados, colimando a impermeabilidade à intervenção da realidade e ao poder criador da jurisprudência, decorrente da crença de que a perfeição da construção conceitual e o encadeamento lógico-dedutivo dos conceitos bastaria para a total compreensão da realidade (BEVILÁQUA, 1906, p. 105); pela pretensão à completude legislativa e plenitude lógica, objetivando abranger, de forma centralizada, toda a legislação e todos os acontecimentos fáticos da vida social (COUTO E SILVA, 1997, p. 17); e pela adoção, com a utilização de uma linguagem precisa, da técnica legislativa da casuística, sem espaço para cláusulas gerais, salvo poucas exceções (GIORGIANNI, 1998, p. 36). 
No que toca ao conteúdo axiológico, são peculiares à codificação oitocentista, além do patriarcalismo, o individualismo e o patrimonialismo, representados pelos dogmas da liberdade e da igualdade formais, com a consagração dos institutos da propriedade, da liberdade contratual e das sucessões como absolutos; instrumentos para a atuação da autonomia da vontade plena e irrestrita dos particulares, em relação aos quais a lei se limitava a estabelecer procedimentos e esquemas de ação (MARTINS-COSTA, 1998, p. 37).

A conjugação dos sistemas interno e externo, fechados na elaboração, interpretação e aplicação das codificações oitocentistas importou na concepção dos códigos como certos e imutáveis, destinados à perenidade e à formação da unívoca realidade do direito (MEIRELLES, 1998, p. 221). Valia o mundo da segurança, o mundo dos códigos, diante da cambiante e flexível realidade sociocultural (MEIRELLES, 1998, p. 221).

\section{INFLUÊNCIAS TEÓRICAS DO ANTIGO DIPLOMA CIVILISTA}

Ao revés do senso comum teórico imperante (WARAT, 2004, p. 32), a codificação civil de 1916, discrepando do Código Civil Português de 1867 e dos demais códigos latino-americanos editados nos meandros de 1900, não sofreu robusta influência do Código Civil Napoleônico (MOREIRA ALVES, 1988, p. 65), em decorrência, precipuamente, da tradição centralista e do bartolismo (PONTES DE MIRANDA, 1981, p. 101). Por outro lado, embora o Código Civil de Beviláqua somente tenha entrado em vigor em 1917, não foi, como refere Pontes de Miranda (1981, p. 108), revisto em virtude do advento, respectivamente em 1896 e 1907, do BGB e do Código Civil Suíço. As alterações verificadas entre 1899 e 1915 foram, em sua maioria, apenas formais, resultantes precipuamente das críticas de Rui Barbosa. 
Para se compreende de forma minudente o arcabouço teorético do Código de 16, imprescindível a análise do pensamento do jurisconsulto Teixeira de Freitas, que no lúcido escólio de Pontes de Miranda (1981, pg. 63) foi, no século XIX, o gênio do direito civil na América. A Consolidação das Leis Civis, cujas notas são magníficas fontes de doutrina, e o Esboço do Código Civil representam o que de melhor se tinha, em direito civil, em todo o continente.

Preciosas são as palavras lançadas por Pontes de Miranda (1981, p. 66):

Foi Teixeira de Freitas o primeiro jurista a quem, após não expressivas tentativas de codificação, se atribuiu a tarefa proceder à elaboração do Código Civil, que, no entanto, deveria ser antecedida da consolidação do direito vigente. Ao proceder à consolidação da caótica legislação esparsa, Teixeira de Freitas procurou criar um real sistema no Direito Civil Pátrio, tarefa à qual se dedicou, inicialmente, quando da elaboração da Consolidação das Leis Civis, concluída em 1857, e, ulteriormente, do Esboço do Código Civil. Com tal desiderato, buscou examinar as leis em seus próprios textos, sem influência de alheias opiniões, para conhecer a substância viva da Legislação. Essa concepção, de sistematizar um Direito Civil positivo pátrio, aplicada à Consolidação, significou uma vultosa mudança de rumo em relação à tradição do Bartolismo, que, primordialmente pela falta de critérios que sua aplicação denotava, tornava tormentosa a prática judiciária.

A concepção filosófica empregada nesse processo de sistematização encontra suas raízes no pensamento de Leibniz, jusracionalista alemão, tendo Teixeira de Freitas adotado, na Consolidação, o supremo princípio de Leibniz, de que a verdadeira classificação deve ser derivada da natureza das coisas, o que é evidenciado, dentre outros aspectos, pelas referências, na Consolidação e no Esboço, à substância viva da Legislação, ao ser das coisas (MARQUES, 1987, p. 11).

Inobstante o indubitável permeio filosófico de Leibniz, a 
concepção sistemática empregada por Teixeira de Freitas não se confunde àquela jusracionalista, em virtude da clarividente influência pandectística (CARVALHO, 1984, p. 2). Isto é, lapidou o edifício organizacional da consolidação com espeque na bipartição da codificação insculpida nos tratados pandectistas (CARVALHO, 1984, p. 4). Tal bipartição se desvelava na cisão estrutural do código em parte geral, discorrendo sobre os "elementos constitutivos de toda relação jurídica", e uma parte especial, destinada ao regramento dos direitos reais e pessoais (CARVALHO, 1984, p. 5). Acerca do tema, mais uma vez, o multicitado Carvalho (1984, pg. 6) nos brinda com a seguinte ensinança:

Colimando a unificação do Direito Privado, desinteressouse do Projeto, pois considerava arbitrária a divisão entre o direito civil e o comercial, propondo, na célebre carta dirigida a Martim Francisco, a elaboração de dois códigos: um Código Geral ou Código Geral de Direito Privado, propedêutico ao conjunto dos ramos jurídicos, e um Código Civil, que absorveria a legislação mercantil. Essa proposta denota a maior tentativa que se fez até hoje de se transpor para a lei uma teoria geral do direito, de conversão em jurídico do jurídico-científico. A não-aceitação de sua proposta importou com que fosse, em 1872, declarada a resolução de seu contrato para a elaboração do Código Civil. Embora não tenha atuado diretamente na elaboração do Código de 1916, suas influências sobre este são significativas. Como refere Pontes de Miranda, Clóvis Beviláqua elaborou, em 1899, o Código Civil de 1916 aproveitando, primordialmente, os projetos de Teixeira de Freitas, de A. Coelho Rodrigues e de Felício dos Santos, sendo que a presença criativa de Teixeira de Freitas na codificação de 1916 foi mais acentuada do que a do próprio Clóvis Beviláqua. A influência do pensamento de Teixeira de Freitas estende-se até o Código Civil de 2002, primordialmente no que tange à sua concepção de sistema, à unificação do direito das obrigações e à concretitude.

Posteriormente, sob a pena de insignes juristas tais como 
Tobias Barreto, Clóvis Beviláqua e Rui Barbosa - expoentes da intitulada "Escola Alemã do Recife", de prevalente inspiração na obra do historicismo de Savigny - (MOREIRA ALVES, 1988 , p. 54), conjuntamente com a supramencionada inspiração filosófica leibniziana, cristalizada na obra de Teixera de Freitas e da influência do Código Napoleônico, o Código Civil de 1916 foi elaborado (COUTO E SILVA, 1997, p. 61).

\section{O CONTRATO E A ORDEM JURÍDICA ENTÃO VIGORANTE}

Prima facie, insta gizar que a noção de qualquer instrumento ou instituto jurídico está circunscrita ao seu ser-aí-nomundo (HEIDEGGER, 1993, p. 233). Significa perlustrar que o contrato não existe de modo isolado, mas plasmado no contexto histórico-cultural da ordem jurídica que o insere. Roppo (1988, p. 24) assevera:

Uma vez que o contrato reflete, pela sua natureza, operações econômicas, é evidente que o seu papel no quadro do sistema resulta determinado pelo gênero e pela quantidade das operações econômicas a que é chamado a conferir dignidade legal, para além do modo como, entre si, se relacionam - numa palavra pelo modelo de organização econômica a cada momento prevalecente. Analogamente, se é verdade que a sua disciplina jurídica - que resulta definida pelas leis e pelas regras jurisprudenciais - corresponde instrumentalmente à realização dos objetivos e interesses valorados consoante as opções políticas e, por isso mesmo, contingentes e historicamente mutáveis, daí resulta que o próprio modo de ser e de se conformar do contrato como instituto jurídico, não pode deixar de sofrer a influência decisiva do tipo de organização político-social a cada momento afirmada. Tudo isto se exprime através da fórmula da relatividade do contrato (como aliás de todos os institutos jurídicos): o contrato muda a sua disciplina, as suas funções, a sua própria estrutura segundo o contexto econômico-social em que está inserido 
Günther Teubner (1999, p. 11) considera que há três níveis diferentes de formação do que chama de sistema contratual: 1) o nível das relações pessoais entre as partes contratantes (nível de interação); 2) o nível do mercado e da organização, que vai além do mero contrato individual (nível institucional); 3) o nível da inter-relação entre os grandes subsistemas sociais, como política, economia e direito (nível social). Acrescenta o autor (1991, p. 13):

Estes níveis devem ser entendidos não como patamares hierárquicos, mas antes como modos distintos de desenvolvimento do sistema tornados gradualmente independentes uns dos outros, que encontram no contrato, a que todos estão ligados, uma espécie de ponto comum. No plano da interação, percebe-se que as normas contratuais formalizadas no acordo negocial precisam ser complementadas por um feixe de expectativas informais, cuja origem não pode decerto encontrar-se nas explícitas declarações de vontade das partes, mas que, ao mesmo tempo, não podem ser simplesmente derivadas de uma interpretação ex lege das normas jurídicas estatais modeladoras do figurino contratual. No plano institucional, estão em causa conexões designadamente com o mercado. Constata-se que os contratos estão integrados num contexto institucional mais vasto, que o direito contratual deve levar em conta. Deve-se buscar a adaptabilidade das obrigações contratuais às estruturas institucionais (o que o clássico direito dos contratos é incapaz de realizar), ora mediante a imposição de obrigações contratuais adicionais (anexas às estipuladas pelas partes), ora através da limitação de direitos decorrentes do contrato, com o emprego da técnica de legislar por cláusulas gerais.

O contrato era a máxima (e quiçá, própria) expressão da autonomia privada, reconhecendo-se aos agentes a liberalidade de estipularem o negócio a seu bel talante. O instituto era serviçal do modelo capitalista-burguês. Fornecia os meios simples e seguros para eficácia de todas as combinações de interesse. Nos dizeres de Dantas (1952, p. 5): 
Não há exagero em dizer que o direito contratual foi um dos instrumentos mais eficazes da expansão capitalista em sua primeira etapa. E, se é certo que deixou de proteger os socialmente fracos, criou oportunidades amplas para os socialmente fortes, que emergiam de todas as camadas sociais, aceitando riscos e fundando novas riquezas.

A noção de autonomia contratual havia sido erigida como projeção da liberdade individual, ao mesmo tempo em que se atribuía à vontade o papel de criar direitos e obrigações (MACHADO, 1991, p. 642). A força cogente do contrato (pacta sunt servanda) era o imperativo categórico (KANT, 2004, p. 122) do corolário da noção de direito subjetivo,-potestade conferida ao credor em face do devedor, corroborando o que se convencionou nomear de "autodeterminação da lex inter partes" (VILELLA, 1978, p. 35), que não sofria a intervenção do legislador e, outrossim, não se submetia ao controle jurisdicional.

Epitomizando a noção de liberdade, Vilella (1978, p. 37) (re)lembra a estado d'arte de outrora:

A autonomia privada era entronizada como garantia da liberdade dos cidadãos em face do Estado, não se buscando a justiça substancial. O eixo da relação contratual era a tutela subjetiva da vontade. A discussão do contrato no século XIX se prendia em larga medida ao acordo de vontades, à averiguação da conformidade entre vontade e declaração e aos vícios do consentimento. Interessava determinar as circunstâncias em que o consentimento se exprimia, e sobretudo se era livre. Pode-se notar que os atores do direito privado tradicional (o proprietário, o credor, o devedor, o marido, o testador etc.) são geralmente descritos de um modo bastante abstrato. Suas características são definidas a partir de uma sistematização uniformizadora dos problemas práticos. No âmbito dos contratos, as pessoas ora são "compradoras", ora "vendedoras", "locadoras" ou "locatárias", "mutuantes" ou "mutuárias" e assim por diante. Entretanto, "as pessoas reais desempenhando tais papéis são 
completamente intercambiáveis".

Nos meandros do arquétipo tradicional, portanto, as mesmas regras devem ser aplicadas independentemente da pessoa concreta que exista em um determinado caso particular, haja vista a abstração reinante e o princípio de igualdade perante a lei.

\section{PRINCÍPIOS (ENTÃO) INFORMADORES DO CONTRATO}

O Direito Contratual sempre deteve por imanência lógica um "quadro de referência principiológica" (NEGREIROS, 2002 , p. 205). Ademais, não se pode descurar que a principiologia no código de outrora exercia evidente valor simbólico, operativo, performático e prospectivo que advinha do fetichismo da lei, haja vista estarem tão somente implícitos no sistema, sem qualquer regramento explícito (AMARAL NETO, 1999, p. 30).

Judith Martins-Costa (2005, p. 42) com a maestria que the é peculiar, verbera que:

A ausência de explicitação dos princípios, no Código de 1916, era uma ausência eloquente: indicava um certo papel atribuído aos princípios na compreensão, construção, interpretação e na aplicação do Direito. Estes não eram tidos como verdadeiras normas jurídicas, tinham papel apenas supletivo ou argumentativo, sendo chamados a atuar no caso de lacunas ou para confirmar a razão de ser de determinada regra.

Conforme delineado por Diez-Pícazo (1972, p. 67), arquissabido que o pensamento jurídico do século XIX foi amplamente assentado no dogma da vontade. Conseguintemente, exsurgiu a tríade formadora da principiologia contratual: a) liberdade de contratar; b) força obrigatória do contrato; c) relatividade.

Discorrendo de forma a intercontextualizar os postulados, Oliveira (1984, p. 12) aviva que: 
A liberdade contratual, entrevista em perspectiva substancial, manifesta-se no momento da conclusão do contrato e engloba uma tríplice faculdade: contratar ou não; escolher a pessoa do contratante; determinar livremente (embora de acordo com a outra parte) as cláusulas do contrato. No aspecto puramente formal, a liberdade contratual também permite aos contratantes a escolha da forma do contrato: a vontade consensual das partes (princípio do consensualismo) ostenta-se suficiente e soberana para atingir validamente os fins visados pelas partes.

Em tal perspectiva, não é difícil constatar a importância do consentimento em tal sistema, considerado como elemento essencial do contrato. Se a vontade é autônoma, o contrato obviamente haverá de ter força obrigatória, impondo-se não somente às partes, mas também ao órgão judicial. Vedada estará, evidentemente, a intervenção do Judiciário para desfazer o contrato ou modificá-lo, à vista de considerações equitativas, mesmo em presença de uma evolução imprevisível e consideravelmente desequilibrada da convenção. A lesão, vale dizer, o desequilíbrio das prestações ao momento da formação do contrato - livremente assumido - , não haverá de justificar a anulação do pacto, salvo casos excepcionais.

Finalmente, o princípio da autonomia exibe como corolário lógico o efeito relativo do contrato, no sentido de que a convenção só gera efeitos em relação às partes contratantes, não podendo prejudicar ou beneficiar terceiros, ante a total ausência de vontade destes últimos.

Destarte, toda arqueologia principiológica gravitava ao entorno da autonomia da vontade, como consectário-lógico da cosmovisão grega. Afinal, desde Sófocles e sua dádiva do Prometeu acorrentado (CASTORIADIS, 2004, p. 46), a liberdade está no coração do homem - é sua autoderminação e criação -, sendo que por intermédio do direito, as pessoas conseguem existir em comunidade.

Não se pode confundir, entretanto, a recusa à ideia de ser a liberdade objeto de um consentimento heterônomo com a ex- 
tensão, desta mesma ideia, à autonomia privada: ao diferenciar-se a liberdade (conceito político e filosófico) da autonomia privada (conceito técnico-jurídico) percebeu-se que esta corresponde a um espaço de liberdade jurígena e, portanto, atribuída, pelo Direito, às pessoas, podendo definir-se como uma permissão genérica de produção de efeitos jurídicos (MENEZES CORDEIRO, 2000, p. 217).

Referida autonomia, representada pelo voluntarismo, estava na base da estruturação do Direito obrigacional moderno, servindo para explicar tanto o contrato quanto a responsabilidade civil, justificando o primeiro como manifestação da "autonomia da vontade" e o dever de indenizar como consequência de um agir culposo, uma vez que a culpa era, nesse modelo bipolar, subsumida na imputabilidade a uma vontade livre e consciente que poderia ter movido a ação a um agir não culposo (PELLICANI, 1980, p. 28).

\section{CONCLUSÕES}

Derradeiramente, pode-se chegar às seguintes conclusões, todas de alguma forma - seja expressa ou implicitamente - enfrentadas no corpo do preste trabalho:

a. O Estado Liberal de Direito, face à imperiosa necessidade de solapar, ou ao menos, mitigar os incites e desmandos d'um regime que lhe antecedera, erigiu como vetor fundamente o princípio da legalidade como sua gênese;

b. Na tradição anglo-saxônica a legislação pôde ser conjurada com demais valores, exsurgindo um sistema jurídico complexo (common Law), enquanto que nos países de tradição romano-germânica, o direito foi amesquinhado à tão somente a lei;

c. O direito estaria na norma jurígena, cuja validação não pressuporia a interligação com um ideal de justiça, mas 
somente de ter sido produzida por autoridade dotada de competência legiferante;

d. O princípio da legalidade era metanorma de reconhecimento das normas vigentes, acrescendo que, segundo tal primado, a norma jurídica existe e é válida em razão das formas de sua produção;

e. O Código Beviláqua detinha espírito individualista, liberal em matéria econômica, conservador ao extremo nas relações familiares, justamente em decorrência de ser servil ao princípio da legalidade;

f. A codificação civil liberal de antanho, de feição hialinamente individualista, detinha como valor indissociável à sua estrutura a realização da pessoa na e para sua propriedade. Em torno da propriedade gravitavam as demais pretensões e garantias do indivíduo - máxime de interesses privados tuteláveis;

g. As relações civis eram eminentemente de cariz patrimonializante, bastando recordar que seus principais institutos eram a propriedade e o contrato;

h. As codificações oitocentistas, como o Código Civil de 1916, estão assentadas em sistemáticas metodológicas "internas" e "fechadas", caracterizando-se pela unicidade das fontes legislativas, haja vista a Teoria Monista das Fontes do Direito então vigorante;

i. O Código Civil de 1916, no que tange à metodologia: consubstanciava um sistema fechado, colimando a impermeabilidade à intervenção da realidade e ao poder criador da jurisprudência, decorrente da crença de que a perfeição da construção conceitual e o encadeamento lógico-dedutivo dos conceitos bastaria para a total compreensão da realidade; pela pretensão à completude legislativa e plenitude lógica, objetivando abranger, de forma centraliza- 
da, toda a legislação e todos os acontecimentos fáticos da vida social; e pela adoção, com a utilização de uma linguagem precisa, da técnica legislativa da casuística, sem espaço para cláusulas gerais, salvo poucas exceções;

j. A concepção filosófica empregada no processo de sistematização encontra suas raízes no pensamento de Leibniz, jusracionalista alemão;

k. Há três níveis diferentes de formação do que chama de sistema contratual: 1) o nível das relações pessoais entre as partes contratantes (nível de interação); 2) o nível do mercado e da organização, que vai além do mero contrato individual (nível institucional); 3) o nível da inter-relação entre os grandes subsistemas sociais, como política, economia e direito (nível social);

1. A principiologia no código de outrora exercia evidente valor simbólico, operativo, performático e prospectivo que advinha do fetichismo da lei, haja vista estarem tão somente implícitos no sistema, sem qualquer regramento explícito.

\section{REFERÊNCIAS}

ACKERMAN, Bruce A. We the people: foundations. Cambridge: Harvard University Press, 1991, v. 1.

AMARALR NETO, Francisco dos Santos. Autonomia privada. Revista do CEJ-Cetro de Estudos Judiciários. Brasília: Conselho da Justiça Federal, n. 9, 1999.

AMARAL NETO, Francisco dos Santos. A técnica jurídica na obra de Freitas. Revista de Direito Civil, São Paulo, v. 38, 1988.

ARGUELLES, Juan Ramón de Páramo; ROIG, Francisco Javier Ansuátegui. Los derechos em La Revolución Inglesa. Madrid: Dykinson, 2003.

BAYNES, Kenneth. Rights as critique and the critique of rights. Stage Publications, v. 28, n. $4,2000$.

BEVILÁQUA, Clovis. Em defeza do projecto de código civil brazileiro. Rio de Janeiro: Francisco Alves, 1906.

BICKEL, Alexander. The least dangerous branch. New Haven: Yale University Press, 
1986.

CACHAPUZ, Maria Cláudia Mércio. O conceito de totalidade concreta aplicado ao sistema jurídico aberto. Revista da Ajuris, n. 33, Porto Alegre, 2004.

CANARIS, Claus-Wilhelm. A influência dos direitos fundamentais sobre o direito privado na Alemanha. In: SARLET, Ingo Wolfgang (org.). Constituição, direitos fundamentais e direito privado. Porto Alegre: Livraria do Advogado, 2003.

CANARIS, Claus Wilhem. Pensamento sistemático e conceito de sistema na ciência do direito. Trad. Menezes Cordeiro. Lisboa: Fundação Calouste Gulbenkian, 1989.

CARVALHO, Orlando de. Teixeira de Freitas e a unificação do direito privado. Boletim da Faculdade de Direito da Universidade de Coimbra, Coimbra, n. LX, 1984.

CASTORIADIS, Cornelius. Antropogonia em Ésquilo e autocriação do homem em Sófocles. In: Figuras do pensável: as encruzilhadas do labirinto. Rio de Janeiro: Civilização Brasileira, 2004.

COUTO E SILVA, Clóvis. O Direito Civil brasileiro em perspectiva histórica e visão do futuro. Revista da Ajuris, n. 40. Porto Alegre, 1987.

COUTO E SILVA, Almiro. Romanismo e Germanismo no Código Civil Brasileiro. Revista da Faculdade de Direito da UFRGS, Porto Alegre, v. 13, 1997.

DANTAS, Francisco de San Tiago. Evolução contemporânea do direito contratual. Rio de Janeiro: Revista Forense, v. 139, 1952.

DÍEZ-PICAZO, Luiz. Fundamentos del derecho civil patrimonial (introdución, teoria del contrato, las relaciones obligatorias). Madrid: Tecnos, 1972.

FACHIN, Luiz Edson. Teoria crítica do direito civil. 2. Ed. Rio de Janeiro: Renovar, 2003.

FERRAJOLI, Luigi. Derechos fundamentales: los fundamentos de los derechos fundamentales. Madrid: Trotta, 2001.

GADAMER, Hans-Georg. Verdade e método: traços fundamentais de uma hermenêutica filosófica. Trad. Flávio Paulo Meurer. 4. ed. Petropólis: Vozes, 200. Vol. 1.

GARDIES, Jean-Loius. La rationalitè du droit chez Leibniz. Archives de philosofie du Droit. Paris, 1978.

GIORGIANNI, Michele. O direito privado e suas atuais fronteiras. Revista dos Tribunais, São Paulo, v. 747, 1998.

GUASTINI, Riccardo. Teoria e dogmatica delle fonti. In: CICU, Antonio; MESSINEO, Francesco; MENGONI, Luigi (orgs.). Trattado di diritto civile e comerciale. Milano: Giuffrè, 1998.

HEIDEGGER, Martin. Sein und Zeit. Tübingen: Max Niemeyer, 1960. (Trad. bras. de Márcia Cavalcante, Ser e Tempo, Petrópolis, Vozes, 1993; volume I).

IRTI, Natalino. L'età della decodificazione. Milão: Giuffré, 1979.

KANT, Immanuel. Fundamentação da metafísica dos costumes e outros escritos. São Paulo: Martin Claret, 2004.

KELSEN, Hans. Teoria pura do direito. São Paulo: Martins Fontes, 1987. 
LARENZ, Karl. Metodologia da ciência do direito. Trad. José Lamego, 3.ed. Lisboa: Fundação Calouste Gulbenkian, 1997.

LÔBO, Paulo Luiz Netto. O contrato: exigências e concepções atuais. São Paulo: Saraiva, 1986.

LORENZETTI, Ricardo Luis. Fundamentos do direito privado. Trad. Vera Jacob de Fradera, São Paulo: Revista dos Tribunais, 1998.

MACHADO, João Batista. Do princípio da liberdade contratual. Braga: Scientia Iuridica, 1991.

MARQUES, Claudia Lima. Cem anos de código civil alemão: O BGB de 1986 e o código civil brasileiro de 1916. Revista da Ajuris, Porto Alegre, n. 40, 1987.

MARTINS-COSTA, Judith. O direito privado como um sistema em construção. Revista de Informação Legislativa, Brasília, v. 35, n. 139, 1998.

MARTINS-COSTA, Judith. Reflexões sobre o princípio da função social dos contratos. Revista de Direito GV, n.1, São Paulo: sem editora, 2005.

MEIRELLES, Jussara. O ser e o ter na codificação civil brasileira: do sujeito virtual à clausura patrimonial. In: FACHIN, Luiz Edson (org.) Repensando fundamentos do direito civil brasileiro contemporâneo. Rio de Janeiro: Renovar, 1998.

MELLO, Cláudio Ari. Democracia constitucional e direitos fundamentais. Porto Alegre: Livraria do Advogado, 2004.

MENEZES CORDEIRO, António. O tratado de direito civil português. 2. ed. Coimbra: Almedina, 2000.

MOREIRA ALVES, José Carlos. A parte geral do projeto de código civil brasileiro. São Paulo: Saraiva, 1988.

NEDEL, Antônio. Uma tópica jurídica: clareira para a emergência do direito. Porto Alegre: Livraria do Advogado, 2006.

NEGREIROS, Teresa de Abreu Trigo Paiva de. Teoria dos contratos: novos paradigmas. Rio de Janeiro: Renovar, 2002.

NORR, Knut Wolfgang. Alcuni momenti della storiografia del diritto. Trad. Rosaria Giordano. Rivista di Diritto Processuale. Padova: Cedam, 2004.

OLIVEIRA, Carlos Alberto Alvaro de. A evolução do direito privado e os princípios contratuais. Revista da Ajuris, n. 32. Porto Alegre, 1984.

OLIVEIRA, Carlos Alberto Alvaro de. Procedimento e ideologia no direito brasileiro atual. Revista da Ajuris, n. 33. Porto Alegre, 1985.

PELLICANI, Luciano. La riscoperta dell'autonomia privata. Rivista di Diritto Civile, Padova: Cedam, 1980.

PERLINGIERI, Pietro. Il diritto civille nella legalità constitucionale. Torino: Schientifiche Italiane, 1991.

PONTES DE MIRANDA, Francisco Cavalcantti. Fontes e evolução do direito civil brasileiro. Rio de Janeiro: Forense, 1981.

REALE, Miguel. Memórias: a balança e a espada. São Paulo: Saraiva, 1987. 
RODRIGUEZ, Carlos Eduardo Lopes. A noção de sistema no direito privado: unidade ou pluralidade. Revista da Faculdade de Direito da Universidade Federal do Rio Grande do Sul, v. 9, n. 1, novembro de 1993.

ROPPO, Enzo. O contrato. Coimba: Almedida, 1988.

SCHMITT, Carl. Teoría de la Constitución. Madrid: Alianza, 1982.

VILELLA, João Baptista. Por uma nova teoria dos contratos. Rio de Janeiro: Revista Forense, v. 261, 1978.

WARAT, Luis Alberto. Epistemologia e ensino do direito: o sonho acabou. Florianópolis: Fundação Boiteux, 2004.

ZAGREBELSKI, Gustavo. El derecho dúctil. Madrid: Trotta, 2005.

Artigo recebido em: 05/05/2017

Artigo aprovado em: 06/10/2017 